ments of academic knowledge, but, through compulsion of repetition, every detail of culture and discipline essential to usefulness to the community and the state."

The appendix contains a valuable list of references for those who are interested in educational theory. The author's analytical index is usually complete; it might be taken as a model.

UNIVERSITY OF ILLINOIS

Lotus D. Coffman

Causes and Effects in American History. By EDwIN W. Morse. New York: Scribner, I912. Pp. viii+289.

The title of Mr. Morse's book leads one to expect a philosophical essay on the principles that underlie our national development, or at least a disquisition on the spirit of our institutions. Instead, the reviewer has found only the narrative of the leading events of our history from the days of Eric the Red to Roosevelt, retold in pleasing style and with substantial accuracy, but without a shadow of justification of the promise of the preface to "ignore details" and deal "not so much with facts as with causes and effects-with the large currents of thought, feeling, and action which from generation to generation, especially through the economic and intellectual influences of each period, have modified and shaped the doctrines of the American people." A comparison of almost any chapter of Mr. Morse's little book with a corresponding chapter in one of our better textbooks in American history will convince the reader that one account might be substituted for the other without serious injury to the unity of the work.

Compared with the failure of the book to live up to the promise of the title and the assurances of the preface the faults in the text itself are insignificant. It is perhaps a bootless task to sift out each little error that has crept into the pages of a book on history, and call the task a review. But it is also true that slips in fact and obscurities in statement assume greater proportion as they are the less atoned for by some general and striking excellence of the work. In the first fifty pages of Mr. Morse's book we find the following errors: the date of Drake's voyage is given $\mathrm{r}_{570-80}$ (p. r3); Philadelphia is settled in 1682 on p. 28 and in $\mathrm{r} 683$ on p. $3 \mathrm{r}$; Quebec is founded in r6o9 (p. 36); the year $\mathrm{r} 688$ is given both for the accession of William III to the English throne (p. 47) and for the outbreak of the war between England and France (p. 43); the emigrants to Virginia after Charles I's execution consisted of "thousands of men of the best blood in royalist circles in England" (p. 26); eighty years

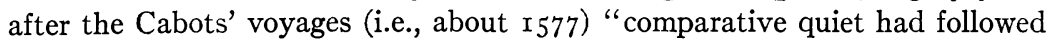
the turmoil of the Reformation" and "the power of Spain was on the decline" (p. ro). There is some obscurity, too, in such a statement as that (on p. 7) "in r $492^{2}$ Spain had superseded Portugal in maritime as in other affairs," and in the discussion of the effect of the Iroquois-Dutch alliance (p. 32) before the description of the event which brought it about (pp. 36, 37). 
With the wealth of economic, social, industrial, educational, commercial, as well as political, data that are at hand, the field is ripe for a study of causes and effects in American history, and the scholar who shall give us such a work will contribute a very valuable chapter to our historical literature.

\section{Barnard College}

David L. Muzzey

\section{A Guide for the Study of Animals. By a Committee from the Biology} Round Table of the Chicago High Schools: Worrallo Whitney, Frederic C. Lucas, Harold B. Shinn, and Mabel E. Smallwood. Boston: D. C. Heath \& Co., I9r. Pp. ix+r97. \$0.50.

This is not a textbook in zoölogy, but a guide for study. It is not merely a laboratory guide, but it gives methods of field and library work. It emphasizes neither morphology, nor physiology, nor ecology, nor the economic importance of animals. It is an all-round book, and interesting in every part.

Chap. i suggests introductory studies of living animals. Its purpose is "to arouse an active, attentive interest on the part of the pupil in various forms of animal life which may be at hand, reminding him of what and how various creatures eat, how they breathe, how they get ideas of the world, how they get about, and perhaps how they succeed where others fail." Seventeen insects (in either the larval or adult form) are suggested for study. These studies are not dependent on one another. Any of them may be omitted if there is not time for all. The suggestions on "getting acquainted with the library" are excellent.

Chap. ii is also on insects. It includes field studies, a key, a general review, and a library exercise.

Chap. iii is entitled "The Connection between Structure and Function." The animal forms studied are protozoa, sponges, coelenterates, and worms. The spirit of the chapter is unique. It is unlike the old-fashioned study of morphology and physiology. The student is directed to watch and see what the animal does, and then question by means of what structure the work of the animal is accomplished.

The classic crayfish is the subject of chap. iv, "Adaptation to Surroundings." The spirit of this chapter is refreshing. It is a new study of an old animal.

Chap. v, "Adaptations for Protection from Enemies," (A) the exo-skeleton, (B) protective coloration, (C) animal associations, (D) protective habits and powers, (E) defensive structures, $(F)$ thesis.

Chap. vi, "Vertebrates." This chapter is very interesting. Studies are made of the following forms: (I) fish and primitive chordates, (2) amphibia (the frog is the type; comparative study of other amphibia), (3) reptiles (snake, Florida lizard, and turtle), (4) birds (pigeon; other birds in field; migration), (5) mammals (several rodents, carnivores, and ungulates).

Chap. vii, "Adaptations for the Preservation of the Species," (A) methods of reproduction, (B) development, (C) protection and care of young, (D) review and library exercise. All that is here is good. The only sin is one of omission. There is nothing satisfactory on vertebrate reproduction. There is work on reproduction of protozoa, on sexual reproduction of coelenterates and echinoderms. There is a morphological study of the hen's egg - the shell, membranes, albumen, yolk, chalazae, and germ spot; but not a suggestion of how eggs are formed in the ovary of the hen 